\title{
Model of Motion of the Combined Manipulator
}

\author{
Vladimir Poletaykin ${ }^{l}$, Pavel Kolesnikov ${ }^{2}$ \\ ${ }^{1}$ Department of Technologies and machinery of environmental engineering of FSBEI HE "Reshetnev Siberian State University of \\ Science and Technology", Krasnoyarsk, Russia. \\ ${ }^{2}$ Department of Vehicles, tractors and forestry machines of FSBEI HE "Reshetnev Siberian State University of Science and \\ Technology", Krasnoyarsk, Russia.
}

\begin{abstract}
The combined manipulators composed of telescopic booms and rotary supports with movable in longitudinal vertical plane columns which provide an increased outreach of operative parts and a bigger service space are widely used in different branches of industry (engineering, transport). The article considers development of mathematical model of kinematic links motion of the combined manipulator with a column movable in longitudinal vertical plane. The mode of load lifting in a synchronous movement of boom and column from the position of picking the load up to the transport position was analyzed.
\end{abstract}

\section{Introduction}

Combined hydraulic manipulators are widely used in production of weight-handling, loading and other machinery. Production and improvement of such machines should be based on studying the dynamics of structural elements. Herewith methods of mathematical modeling are considered to be the most effective. On this basis, researches with the use of mathematical models of combined manipulator links motion mode dynamics focused on validation of kinematics parameters and design of the processing equipment, should be considered as relevant.

\section{Foundation of the calculation model}

Fig. 1 shows the calculation model of the "processing equipment - load" system. The analyzed mode can be used when the manipulator operates as a processing equipment of forestry, road-building, load-lifting and other machines.

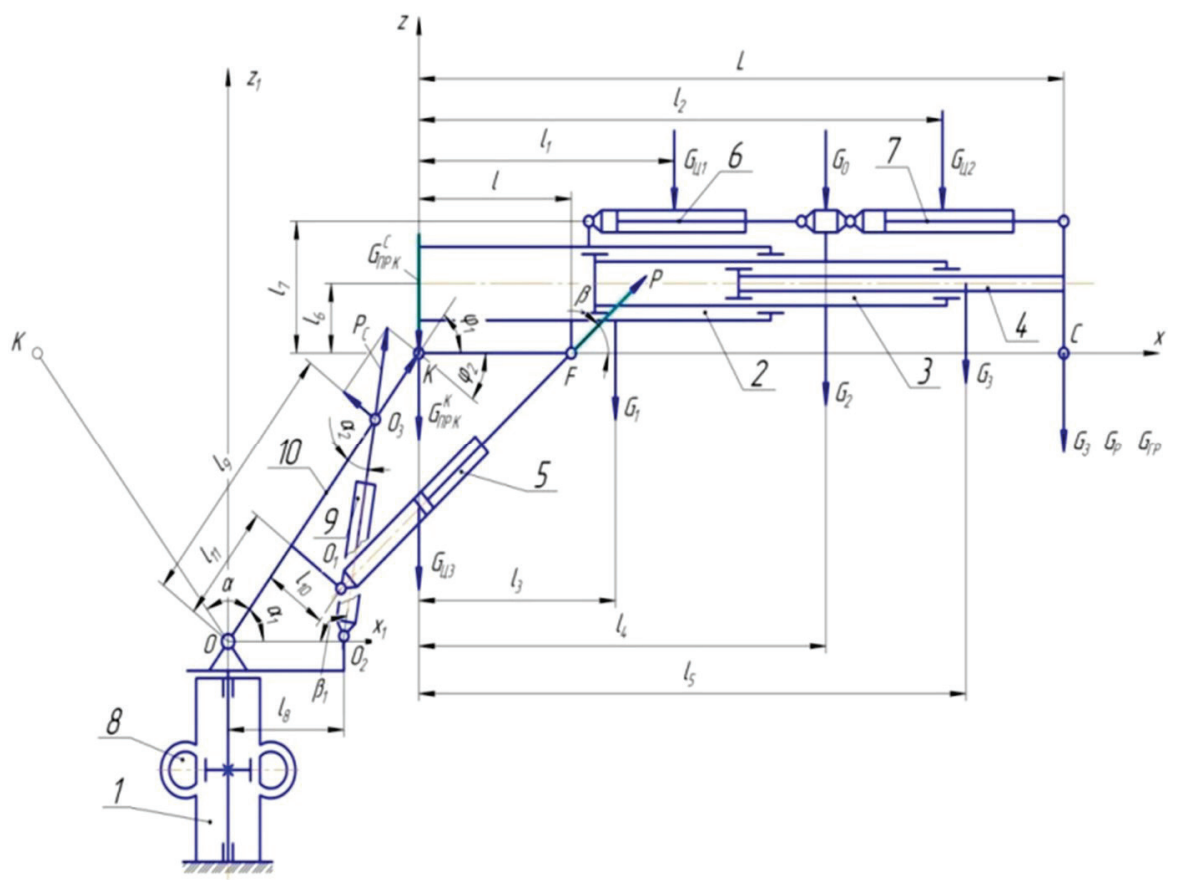

Fig. 1. Calculation diagram of the "processing equipment load" system (manipulator with a tilting column):

1 - rotary support; $2,3,4$ - outer, middle and inner sections of telescopic boom; 5 - boom lift hydraulic cylinder; 6,7 - hydraulic cylinders of sections' telescoping mechanism; 8 - mechanism of manipulator's rotation in horizontal plane; 9 - hydraulic cylinder of column rotation; $10-$ column; $\mathrm{O} 1 \mathrm{~K}=\mathrm{C} ; \mathrm{OO} 2=\ell 8=\mathrm{C} 1$

\footnotetext{
* Corresponding author: atlm@sibsau.ru
}

(C) The Authors, published by EDP Sciences. This is an open access article distributed under the terms of the Creative Commons Attribution License 4.0 (http://creativecommons.org/licenses/by/4.0/). 
When working element picks the load up, the telescopic boom brings it to the machine by retraction of sections, then the load is set to the transport position by actuation of column rotation hydraulic cylinder (CRHC) and boom lift (BL). Meanwhile the boom rotates around $\mathrm{K}$-axis, and the column rotates around $\mathrm{O}$-axis. Rotation angle of the boom is $\varphi$ (relative motion), rotation angle of the column is $\alpha$ (transportation motion). Reference point of the angle $\varphi$ is the lower limit position of the boom; reference point of the angle $\alpha$ is the rightmost position of the column.

Following symbols are used in Fig. 1.

$G_{1}, G_{2}, G_{3}$ : gravitation forces of outer, middle and inner sections of telescopic boom;

$G_{ц 1}, G_{ц 2}, G_{0}$ : gravitation forces of hydraulic cylinders while sections' telescoping and of sections' telescoping mechanism;

$G_{3}, G_{\Gamma \mathrm{P}}, G_{P}$ : gravitation forces of gripping device, load and rotator;

$G_{Ц 3}, G_{Ц 4}$ : gravitation forces of hydraulic cylinders while column rotation and boom lift;

$G_{\Pi \text { П.C }}$ : total gravitation force of structural elements of the boom and the load brought to point $C$;

$P, P_{\mathrm{C}}$ : forces on rods of the column rotation and boom lift hydraulic cylinders;

$L$ : boom dimensions at retracted sections;

$\ell_{1}, \ell_{2}, \ell_{3}, \ell_{4}, \ell_{5}$ : distances from $K$-axis of boom rotation to the centers of structural elements gravity

$\ell_{6}, \ell_{7}, \ell_{8}, \ell_{9}, \ell_{10}, \ell_{11}$ : dimensions of manipulator elements.

Constructing the equations of motion for the "processing equipment - load" system

The boom rotates in ZKX-plane, the column rotates in Z1OX1-plane. The rotation angles $\alpha$ and $\varphi$ clearly determine the positions of this elements of the system in the rotation planes. If dimensions of the boom $L$ and the column $L K$ are known, we can find position of any point by means of specified parameters. Based on this, the system can be considered as a system with two degrees of freedom $(K=2)$ with generalized coordinates $\alpha$ and $\varphi$.

To formulate equations of motion for this mechanical system the Lagrange equations of the 2-nd kind was used. According to the number of degrees of freedom of the system two Lagrange equations were formulated

$$
\begin{aligned}
& \frac{\mathrm{d}}{\mathrm{dt}}\left(\frac{\partial \mathrm{T}}{\partial \dot{\alpha}}\right)-\left(\frac{\partial \mathrm{T}}{\partial \alpha}\right)=\mathrm{Q}_{\alpha}, \\
& \frac{\mathrm{d}}{\mathrm{dt}}\left(\frac{\partial \mathrm{T}}{\partial \dot{\varphi}}\right)-\left(\frac{\partial \mathrm{T}}{\partial \varphi}\right)=\mathrm{Q}_{\varphi}
\end{aligned}
$$

where $\mathrm{Q}_{\alpha}, \mathrm{Q}_{\varphi}$ are generalized forces corresponding to generalized coordinates $\alpha$ and $\varphi$ respectively.

The motional energy of the system is equal to the sum of motional energies of the column and the boom, i.e. the sum of the motional energies of relative and transportation motions

$$
\mathrm{T}=\mathrm{T} 1+\mathrm{T} 2
$$

where T1 is motional energy of the given column mass with the given masses of the structural elements mounted on it (column rotation and boom lift hydraulic cylinders and other elements of the hydraulic actuator); T2 is motional energy of the given mass of the column and the load.
When the telescopic boom rotates, its sections do not telescope, and the dimensions of the boom $\mathrm{L}$ do not change, therefore positions of the mass centers of the structural elements of the boom relatively to the $\mathrm{K}$-axis (radius of mass inertia) remain constant. In this case in order to simplify the determination of the motional energy of the system masses of structural elements of the telescopic boom were brought to point $\mathrm{C}$ (point of suspension of the rotator to the boom). Masses of structural elements of the column were brought to $\mathrm{K}$-axis (mounting axis of the boom). Calculation of the mass of structural elements of the boom mПP.C is based on the condition that motional energy of the reduced mass is equal to the sum of the motional energies of the masses it replaces. Therefore,

$$
\begin{gathered}
\frac{\mathrm{G}_{\Pi \mathrm{CP} .} \dot{\varphi}^{2} \mathrm{~L}^{2}}{2 \mathrm{~g}}=\frac{\dot{\varphi}^{2}}{2 \mathrm{~g}} \cdot\left[\left(\mathrm{G}_{1} \ell_{3}^{2}+\mathrm{G}_{2} \ell_{4}^{2}+\mathrm{G}_{3} \ell_{5}^{2}++\mathrm{G}_{Ц 1} \ell_{2}^{2}+\right.\right. \\
\left.\left.\mathrm{G}_{0} \ell_{4}^{2}+\mathrm{G}_{\mathrm{P}}+\mathrm{G}_{3}+\mathrm{G}_{\Gamma \mathrm{P}}\right)\right]
\end{gathered}
$$

On this basis, the boom mass brought to point $\mathrm{C}$ is

$$
\begin{gathered}
\mathrm{m}_{\Pi \text { ПР.C }}=\frac{\mathrm{G}_{\Pi P . C}}{\mathrm{~g}}=\frac{\mathrm{G}_{1}}{\mathrm{~g}} \cdot \frac{\ell_{3}^{2}}{\mathrm{~L}^{2}}+\frac{\mathrm{G}_{2}}{\mathrm{~g}} \cdot \frac{\ell_{4}^{2}}{\mathrm{~L}^{2}}+\frac{\mathrm{G}_{3}}{\mathrm{~g}} \cdot \frac{\ell_{5}^{2}}{\mathrm{~L}^{2}}+\frac{\mathrm{G}_{Ц 1}}{\mathrm{~g}} \cdot \frac{\ell_{1}^{2}}{\mathrm{~L}^{2}}+ \\
+\frac{\mathrm{G}_{Ц 2}}{\mathrm{~g}} \cdot \frac{\ell_{2}^{2}}{\mathrm{~L}^{2}}++\frac{\mathrm{G}_{0}}{\mathrm{~g}} \cdot \frac{\ell_{4}^{2}}{\mathrm{~L}^{2}}+\frac{\mathrm{G}_{\mathrm{P}}+\mathrm{G}_{3}+\mathrm{G}_{\Gamma \mathrm{P}}}{\mathrm{g}}
\end{gathered}
$$

or

$$
\begin{gathered}
m_{\Pi \mathrm{P} . \mathrm{C}}=m_{1} \frac{\ell_{3}^{2}}{L^{2}}+m_{2} \frac{\ell_{4}^{2}}{L^{2}}+m_{3} \frac{\ell_{5}^{2}}{L^{2}}+ \\
+m_{Ц 1} \frac{\ell_{1}^{2}}{L^{2}}+m_{Ц 2} \frac{\ell_{2}^{2}}{L^{2}}+m_{0} \frac{\ell_{4}^{2}}{L^{2}}+m_{\mathrm{P}}+m_{3}+m_{\Gamma \mathrm{P}}
\end{gathered}
$$

where $m_{1}$ is mass of the outer section of the boom; $m_{2}$ is mass of the middle section of the boom; $m_{3}$ is mass of the inner section of the boom; $m_{Ц 1}, m_{Ц 2}$ are masses of hydraulic cylinders of the sections' telescoping mechanism; $m_{0}$ is mass of the sections' telescoping mechanism; $m_{\mathrm{P}}, m_{3}, m_{\Gamma \mathrm{P}}$ are masses of gripping device, load and rotator.

Mass of the column and structural elements mounted on it brought to point $K$ can be calculated with the following equation:

$$
\begin{aligned}
\frac{\mathrm{G}_{\Pi \mathrm{C} . \mathrm{K}} \dot{\alpha}^{2} \mathrm{~L}_{\mathrm{K}}^{2}}{2 \mathrm{~g}}= & \frac{\mathrm{G}_{\mathrm{K}} \dot{\alpha}^{2}\left(0,5 \mathrm{~L}_{\mathrm{K}}\right)^{2}}{2 \mathrm{~g}}+\frac{0,5 \mathrm{G}_{Ц 3} \dot{\alpha}^{2}(0,5 \ell)^{2}}{2 \mathrm{~g}}+ \\
& +\frac{0,5 \mathrm{G}_{Ц 4} \dot{\alpha}^{2}\left(0,5 \ell_{8}\right)^{2}}{2 \mathrm{~g}}
\end{aligned}
$$

The equation (6) is based on the assumption that gravitation forces of cylinders GЦ3 and GЦ4 are evenly distributed between the boom and the column as well as between the column and the base of the rotary support; points of their application are $0,5 \ell$ and $0,5 \ell 8$ respectively from the mounting axis of the boom (point $K$ ).

According to the equation (6) mass of the column and structural elements mounted on it brought to point $K$ is

$$
\begin{aligned}
& \mathrm{m}_{\Pi \mathrm{R} . \mathrm{K}}=\frac{\mathrm{G}_{\mathrm{K}}}{\mathrm{g}} \cdot \frac{\left(0,5 \mathrm{~L}_{\mathrm{K}}\right)^{2}}{\mathrm{~L}_{\mathrm{K}}^{2}}+\frac{0,5 \mathrm{G}_{Ц 3}}{\mathrm{~g}} \cdot \frac{(0,5 \ell)^{2}}{\mathrm{~L}_{K}^{2}}+\frac{0,5 \mathrm{G}_{Ц 4}\left(0,5 \mathrm{~L}_{K}\right)^{2}}{\mathrm{gL}_{\mathrm{K}}^{2}}= \\
& 0,25 \frac{\mathrm{G}_{\mathrm{K}}}{\mathrm{g}}+0,125 \frac{\mathrm{G}_{Ц 3}}{\mathrm{~g}} \cdot \frac{\ell^{2}}{\mathrm{~L}_{\mathrm{K}}^{2}}+0,125 \mathrm{~m}_{Ц 4} \cdot \frac{\ell_{8}^{2}}{\mathrm{~L}_{\mathrm{K}}^{2}} \\
& \text { or } \mathrm{m}_{\Pi \text { П.К }}=0,25 \mathrm{~m}_{\mathrm{K}}+0,125 \mathrm{~m}_{Ц 3} \cdot \frac{\ell^{2}}{\mathrm{~L}_{K}^{2}}++0,125 \mathrm{~m}_{Ц 4} \cdot \frac{\ell_{8}^{2}}{\mathrm{~L}_{K}^{2}}
\end{aligned}
$$

According to (2) the motional energy of the system is

$$
\mathrm{T}=\mathrm{T} 1+\mathrm{T} 2=\frac{\mathrm{I}_{0} \dot{\alpha}^{2}}{2}+\frac{1}{2}\left(\mathrm{~m}_{\Pi \text { P.C }} \mathrm{V}_{\mathrm{ac}}^{2}+\mathrm{I}_{\mathrm{C}} \dot{\varphi}^{2}\right),
$$


where $I_{0}$ is moment of inertia of the column relative to O-axis, $I_{C}$ is central moment of inertia of the boom assembly; $V_{\text {ac }}$ is an absolute motion velocity of e point $C$ (point of boom mass brining).

The theorem on composition of velocities was applied, according to which absolute velocity of point $\mathrm{C}$ is equal to geometric sum of its transportation and relative velocities

$$
\mathrm{V}_{\mathrm{ac}}^{2}=\mathrm{V}_{\mathrm{ec}}^{2}+\mathrm{V}_{\mathrm{rc}}^{2}+2 \mathrm{~V}_{\mathrm{ec}} \cdot \mathrm{V}_{\mathrm{rc}} \cos \gamma,
$$

where $V_{\mathrm{ec}}, \mathrm{V}_{\mathrm{rc}}$ are velocities of transportation and relative motion of point $\mathrm{C}$,

$\gamma$ is an angle between vector directions of transportation and relative motion of point $\mathrm{C}$.

Fig. 2 shows a diagram for determining velocity of an absolute motion of point $\mathrm{C}-\mathrm{V}_{\mathrm{ac}}$, point of boom and the load mass bringing.

$$
\mathrm{V}_{\mathrm{ec}}=\mathrm{OC} \cdot \dot{\alpha} ; \mathrm{V}_{\mathrm{rc}}=\mathrm{L} \cdot \dot{\varphi} .
$$

According to $\mathrm{OKC}$ triangle

$$
\mathrm{OC}^{2}=\mathrm{L}_{\mathrm{K}}^{2}+\mathrm{L}^{2}-2 \mathrm{~L}_{\mathrm{K}} \cdot \mathrm{L} \cos \left(\varphi_{\mathrm{H}}+\varphi\right) .
$$

According to the same triangle $\mathrm{L}_{\mathrm{K}}^{2}=\mathrm{L}^{2}+\mathrm{OC}^{2}-2 \mathrm{~L}$. $\mathrm{OC} \cdot \cos \mathrm{C}$

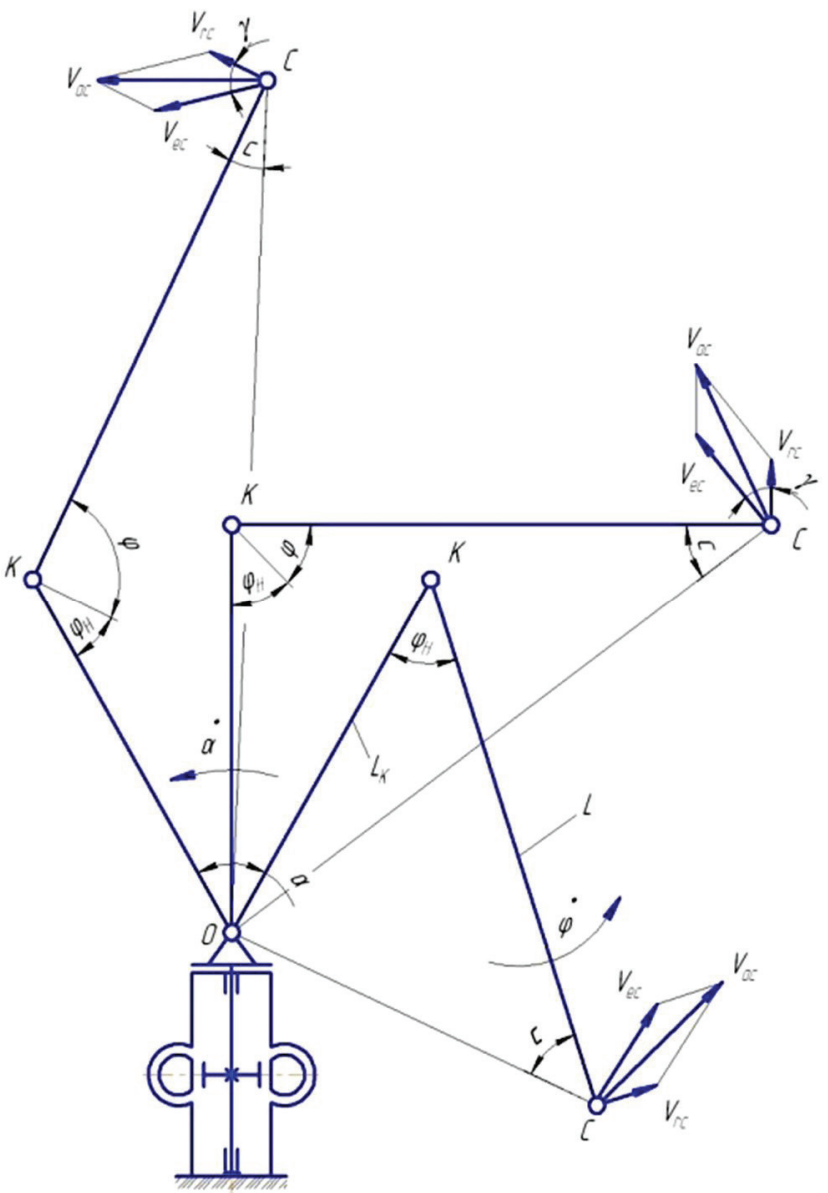

Fig. 2. Diagram for determining velocity of an absolute motion of point $\mathrm{C}$ in synchronous movement of the boom and the column: $\varphi \mathrm{H}$ is an initial angle between the boom and the column; $\varphi$ is rotation angle of the boom (relative motion); $\alpha$ is rotation angle of the column (transportation motion); $\dot{\alpha}, \dot{\varphi}$ are angular velocities of the column and the boom, respectively
Fig. 2 shows, that angles $\gamma$ and $\mathrm{C}$ are equal being angles with mutually perpendicular sides. Thus,

$$
\cos \mathrm{C}=\cos \gamma=\frac{\mathrm{L}^{2}+\mathrm{OC}^{2}-\mathrm{L}_{\mathrm{K}}^{2}}{2 \mathrm{~L} * \mathrm{OC}}
$$

Absolute motion velocity

$\mathrm{V}_{\mathrm{ac}}^{2}=\dot{\alpha}^{2} \cdot \mathrm{OC}^{2}+\dot{\varphi}^{2} \cdot \mathrm{L}^{2}+2 \dot{\alpha} \cdot \dot{\varphi} \cdot \mathrm{L} \cdot \mathrm{OC} \cdot \cos \gamma$.

$\cos \gamma=\cos C$ is expressed by $\cos \left(\varphi_{\mathrm{H}}+\varphi\right)$.

$$
\begin{gathered}
\cos \gamma=\frac{\mathrm{L}^{2}+\mathrm{OC}^{2}-\mathrm{L}_{\mathrm{K}}^{2}}{2 \mathrm{~L} \cdot \mathrm{OC}} \\
=\frac{\mathrm{L}^{2}+\mathrm{L}_{\mathrm{K}}^{2}+\mathrm{L}^{2}-2 \mathrm{~L}_{\mathrm{K}} \cdot \mathrm{L} \cdot \cos \left(\varphi_{\mathrm{H}}+\varphi\right)-\mathrm{L}_{\mathrm{K}}^{2}}{2 \mathrm{~L} \cdot \mathrm{OC}}=\left[\frac{\mathrm{L}^{2}-\mathrm{L}_{\mathrm{K}} \cdot \mathrm{L}}{\mathrm{L} \cdot \mathrm{OC}}\right] \cdot \cos \left(\varphi_{\mathrm{H}}+\varphi\right) .
\end{gathered}
$$

After substituting

$$
\mathrm{V}_{\mathrm{ac}}^{2}=\dot{\alpha}^{2} \mathrm{OC}^{2}+\dot{\varphi}^{2} \cdot \mathrm{L}^{2}+2 \dot{\alpha} \cdot \dot{\varphi} \cdot \mathrm{L} \cdot \mathrm{OC} \cdot\left[\frac{\mathrm{L}^{2}-\mathrm{L}_{\mathrm{K}} * \mathrm{~L}}{\mathrm{~L} * \mathrm{OC}}\right] \cdot \cos \left(\varphi_{\mathrm{H}}+\varphi\right)
$$

In accordance with (10), equation of motional energy looks like the following

$$
\begin{array}{r}
\mathrm{T}=\frac{\mathrm{m}_{\Pi P . \mathrm{K}} \cdot \mathrm{L}_{\mathrm{K}}^{2} \cdot \dot{\alpha}^{2}}{2}+\frac{\mathrm{m}_{\Pi \text { P.C }} \cdot \mathrm{OC}^{2} \cdot \dot{\alpha}^{2}}{2}+\frac{\mathrm{m}_{\Pi \text { P.C }} \cdot \mathrm{L}^{2} \cdot \dot{\varphi}^{2}}{2}+\mathrm{m}_{\Pi P . C} \\
\cdot \mathrm{L} \cdot \mathrm{OC} \cdot \dot{\alpha} \cdot \dot{\varphi} \cdot\left[\frac{\mathrm{L}^{2}-\mathrm{L}_{\mathrm{K}} \cdot \mathrm{L}}{\mathrm{L} \cdot \mathrm{OC}}\right] \cdot \cos \left(\varphi_{\mathrm{H}}+\varphi\right)+\frac{\mathrm{I}_{\mathrm{C}} \cdot \dot{\varphi}^{2}}{2}
\end{array}
$$

Equations of motion for the "processing equipment load" system

By differentiating the equation of the motional energy (11) for the components of the Lagrange equations (1), the following system of equations of motion of the dynamic system of the manipulator is expressed:

$$
\begin{aligned}
\mathrm{m}_{\Pi \text { I.K }} \cdot \mathrm{L}_{\mathrm{K}}^{2} \cdot \ddot{\alpha}+\mathrm{m}_{\Pi \text { P.C. }} \cdot \mathrm{OC}^{2} \cdot \ddot{\alpha}+\mathrm{m}_{\Pi \text { P.C }} \cdot \mathrm{OC} \cdot \mathrm{L} \cdot \ddot{\varphi}\left[\frac{\mathrm{L}^{2}-\mathrm{L}_{\mathrm{K}} \cdot \mathrm{L}}{\mathrm{L} \cdot \mathrm{OC}}\right] \\
\cdot \cos \left(\varphi_{\mathrm{H}}+\varphi\right)-\mathrm{m}_{\Pi \text { P.C }} \cdot \mathrm{OC} \cdot \mathrm{L} \cdot \dot{\varphi}^{2} \cdot\left[\frac{\mathrm{L}^{2}-\mathrm{L}_{\mathrm{K}} \cdot \mathrm{L}}{\mathrm{L} \cdot \mathrm{OC}}\right] \\
\cdot \sin \left(\varphi_{\mathrm{H}}+\varphi\right)=\mathrm{Q}_{\alpha}
\end{aligned}
$$

$$
\begin{gathered}
\left(\mathrm{m}_{\Pi \mathrm{C} . \mathrm{C}} \mathrm{L}^{2}+\mathrm{I}_{\mathrm{C}}\right) \ddot{\varphi}+ \\
+\mathrm{m}_{\Pi \mathrm{P} . \mathrm{C}} \cdot \mathrm{OC} \cdot \ddot{\alpha} \cdot \mathrm{L} \cdot\left[\frac{\mathrm{L}^{2}-\mathrm{L}_{\mathrm{K}} \cdot \mathrm{L}}{\mathrm{L} \cdot \mathrm{OC}}\right] \cdot \cos \left(\varphi_{\mathrm{H}}+\varphi\right)=\mathrm{Q}_{\varphi}
\end{gathered}
$$

Determination of generalized forces $\mathrm{Q} \alpha$ and $\mathrm{Q} \varphi$ corresponding to the generalized system coordinates $\varphi$ and $\alpha$.

To determine generalized forces $\mathrm{Q} \varphi$ and $\mathrm{Q} \alpha$ the principle of possible motions of the system in direction of the increase of generalized coordinates $\varphi$ and $\alpha-\Delta \varphi и \Delta \alpha$ was used. For calculation of the generalized force $\mathrm{Q} \varphi$ one considers $\Delta \alpha=0$, and for calculation of the generalized force $\mathrm{Q} \alpha \Delta \varphi=0$. Gravitation forces of structural elements and load $\mathrm{Gi}$, and forces on rods of the hydraulic cylinders PC and P are considered as active forces. Generalized force is considered as a factor while expressing sum of elementary works of active forces in the direction of possible movement:

$$
\delta \mathrm{A}_{\varphi}=\mathrm{Q}_{\varphi} \cdot \Delta \varphi ; \delta \mathrm{A}_{\alpha}=\mathrm{Q}_{\alpha} \cdot \Delta \alpha .
$$

Let us determine the sum of elementary works of active forces in direction of the generalized coordinate $\varphi$. Herewith $\Delta \varphi \neq 0, \Delta \alpha=0$.

To determine the generalized force $\mathrm{Q} \varphi$ equations (4), (5) of mass of the boom mПР.C brought to point $\mathrm{C}$ in a horizontal position of the boom are used. 


$$
\text { Then } \begin{aligned}
\Sigma \delta \mathrm{A}_{\varphi} & =\left(\mathrm{P} \ell \sin \beta-\mathrm{m}_{\Pi \mathrm{PP} . \mathrm{gL}} \mathrm{g}\right) \Delta \varphi \\
\mathrm{Q}_{\varphi} & =\mathrm{P} \ell \sin \beta-\mathrm{m}_{\Pi \mathrm{P} . \mathrm{g}} \mathrm{gL}
\end{aligned}
$$

Let us determine the sum of elementary works of active forces and gravitation forces of structural elements in direction of generalized coordinate $\alpha$. Herewith $\Delta \varphi=0 ; \Delta \alpha \neq 0$. In the direction of generalized coordinate $\alpha$ active force PC and gravitation forces of structural elements of the boom and the column perform an operation. In order to simplify the equation of generalized force $\mathrm{Q} \alpha$ gravitation forces of structural elements of boom, load and column to the point $\mathrm{K}$ are reduced. In this connection horizontal position of the boom is considered. Bringing the forces to selected points is performed on condition of equality of moments of the reduced force to the sum of moments of reduced forces relative to any point on the plane (Varignon theorem).

In order to determine gravitation force brought to point $\mathrm{K}$, equations of mass of the boom brought to the point $\mathrm{C}$ in a horizontal position of the boom (4), (5) $\mathrm{m \Pi P}$.C are use.

Let us formulate an equation of moments of gravitation force of the boom brought to point $\mathrm{C}\left(\mathrm{G}_{\Pi \mathrm{P} . \mathrm{C}}\right)$ and gravitation force of the boom brought to point $\mathrm{K}\left(\mathrm{G}_{\text {ПР.К. }}^{\mathrm{C}}\right)$ relative to $\mathrm{O}$-axis.

$$
\mathrm{m}_{\text {ПР. } .} \mathrm{g}\left(\mathrm{L}+\mathrm{L}_{\mathrm{K}} \cdot \cos \alpha_{1}\right)=\mathrm{G}_{\Pi \text { П.К }}^{\mathrm{C}} \cdot \mathrm{L}_{\mathrm{K}} \cdot \cos \alpha_{1} .
$$

Therefore, $G_{\Pi P . K}^{C}=\frac{m_{\Pi P . C g}\left(\mathrm{~L}+\mathrm{L}_{\mathrm{K}} \cdot \cos \alpha_{1}\right)}{\mathrm{L}_{\mathrm{K}} \cdot \cos \alpha_{1}}=\frac{\mathrm{m}_{\Pi \mathrm{P} . \mathrm{CgL}}+\mathrm{m}_{\Pi \mathrm{P} . \mathrm{C}} \mathrm{g} \mathrm{L}_{\mathrm{K}} \cdot \cos \alpha_{1}}{\mathrm{~L}_{\mathrm{K}} \cdot \cos \alpha_{1}}$

$$
=\frac{m_{\Pi Р . C g L}}{L_{K} \cdot \cos \alpha_{1}}+m_{\Pi Р . C} g
$$

Now it is necessary to determine gravitation force of structural elements of the column briught to point $\mathrm{K}$ and gravitation force of hydraulic cylinders of GC, GЦ4, GЦ3actuators drive. In doing so equations (7), (8) for determination of reduced mass of the said structural elements to the point $\mathrm{K}$ are used:

$$
\mathrm{G}_{\Pi Р . К}^{\mathrm{K}}=\mathrm{m}_{\Pi Р . \kappa} \mathrm{g}
$$

Then

$$
\begin{gathered}
\Sigma \delta \mathrm{A}_{\alpha}=\left[\mathrm{P}_{\mathrm{C}} \cdot \sin \alpha_{2} \cdot \ell_{9}-\left(\mathrm{G}_{\Pi \mathrm{K} . \mathrm{K}}^{\mathrm{K}}+\mathrm{G}_{\Pi \mathrm{P} . \mathrm{K}}^{\mathrm{C}}\right) \mathrm{L}_{\mathrm{K}} \cdot \cos \alpha_{1}\right] \Delta \alpha \\
\mathrm{Q}_{\alpha}=\mathrm{P}_{\mathrm{C}} \cdot \sin \alpha_{2} \cdot \ell_{9}-\left(\mathrm{G}_{\Pi \mathrm{K} . \mathrm{K}}^{\mathrm{K}}+\mathrm{G}_{\Pi \mathrm{C} . \mathrm{K}}^{\mathrm{C}}\right) \mathrm{L}_{\mathrm{K}} \cdot \cos \alpha_{1} .
\end{gathered}
$$

Since the transportation motion of the system is rotational and while simultaneous rotation of the column and the boom, the distance OC (Fig. 3) is constantly increasing, so there appears repeated rotating (Coriolis) acceleration $\omega \mathrm{C}$ and the Coriolis force $\mathrm{FC}$.

Coriolis acceleration is calculated by the equation

$$
\omega_{\mathrm{C}}=2 \dot{\alpha} \cdot \mathrm{V}_{\mathrm{rc}}=2 \dot{\alpha} \cdot \dot{\varphi} \cdot \mathrm{L}
$$

According to the moment of Coriolis force the generalized force $\mathrm{Q} \alpha$ is calculated in the following way:

$$
\begin{gathered}
\mathrm{Q}_{\alpha}=\mathrm{P}_{\mathrm{C}} \cdot \sin \alpha_{2} \cdot \ell_{9}-\left(\mathrm{G}_{\Pi \mathrm{K} . \mathrm{K}}^{\mathrm{K}}+\mathrm{G}_{\Pi \mathrm{CP.K}}^{\mathrm{C}}\right) \mathrm{L}_{\mathrm{K}} \cdot \cos \alpha_{1}- \\
-2 \mathrm{~m}_{\Pi \mathrm{CP} . \mathrm{C}} \cdot \dot{\alpha} \cdot \dot{\varphi} \cdot \mathrm{L} \cdot \mathrm{L}_{\mathrm{K}} \cdot \cos \gamma_{1} .
\end{gathered}
$$

According to the equations (14) and (17) motions of the considered dynamical system are determined as follows:

$$
\begin{aligned}
& \mathrm{m}_{\text {ПР.К }} \cdot \mathrm{L}_{\mathrm{K}}^{2} \cdot \ddot{\alpha}+\mathrm{m}_{\text {ПР.С. }} \cdot \mathrm{OC}^{2} \cdot \ddot{\alpha}+ \\
& +\mathrm{m}_{\Pi \text { P.C }} \cdot \mathrm{OC} \cdot \mathrm{L} \cdot \ddot{\varphi}\left[\frac{\mathrm{L}^{2}-\mathrm{L}_{\mathrm{K}} \cdot \mathrm{L}}{\mathrm{L} \cdot \mathrm{OC}}\right] \cdot \cos \left(\varphi_{\mathrm{H}}+\varphi\right)-\mathrm{m}_{\Pi \text { P.C }} \cdot \mathrm{OC} \\
& \cdot \mathrm{L} \cdot \dot{\varphi}^{2} \cdot\left[\frac{\mathrm{L}^{2}-\mathrm{L}_{\mathrm{K}} \cdot \mathrm{L}}{\mathrm{L} \cdot \mathrm{OC}}\right] \cdot \sin \left(\varphi_{\mathrm{H}}+\varphi\right)= \\
& =\mathrm{P}_{\mathrm{C}} \cdot \sin \alpha_{2} \cdot \ell_{9}-\left(\mathrm{G}_{\Pi \mathrm{K} . \mathrm{K}}^{\mathrm{K}}+\mathrm{G}_{\Pi \mathrm{C} . \mathrm{K}}^{\mathrm{C}}\right) \mathrm{L}_{\mathrm{K}} \cdot \cos \alpha_{1}- \\
& -2 \mathrm{~m}_{\Pi \mathrm{C} . \mathrm{C}} \cdot \dot{\alpha} \cdot \dot{\varphi} \cdot \mathrm{L} \cdot \mathrm{L}_{\mathrm{K}} \cdot \cos \gamma_{1} \cdot\left(\mathrm{m}_{\Pi \mathrm{CP} C} \mathrm{~L}^{2}+\mathrm{I}_{\mathrm{C}}\right) \ddot{\varphi}+ \\
& +\mathrm{m}_{\text {ПР.C }} \cdot \mathrm{OC} \cdot \ddot{\alpha} \cdot \mathrm{L} \cdot\left[\frac{\mathrm{L}^{2}-\mathrm{L}_{\mathrm{K}} \cdot \mathrm{L}}{\mathrm{L} \cdot \mathrm{OC}}\right] \cdot \cos \left(\varphi_{\mathrm{H}}+\varphi\right)= \\
& =\mathrm{P} \ell \sin \beta-\mathrm{m}_{\Pi \mathrm{CP} . \mathrm{g}} \mathrm{gL}
\end{aligned}
$$

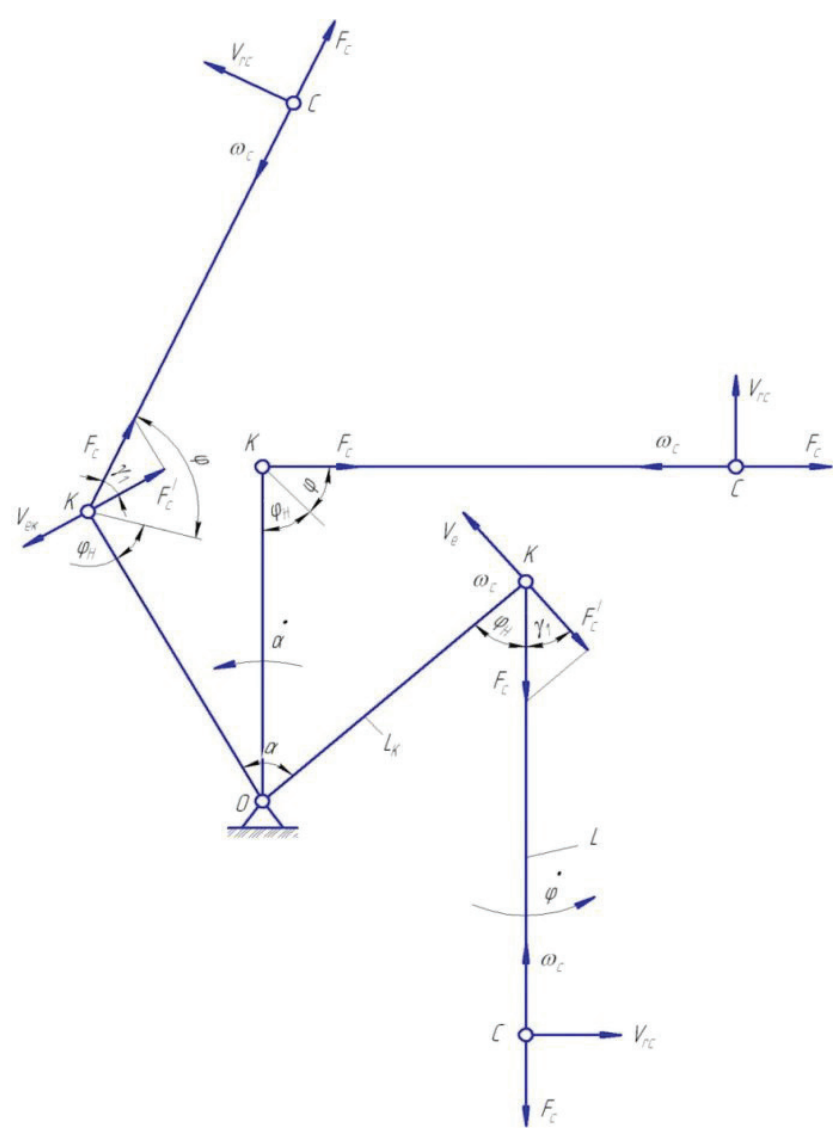

Fig. 3. Diagram for determination of Coriolis acceleration and Coriolis forces: $\omega \mathrm{C}$ is Coriolis acceleration, $\mathrm{FC}$ is Coriolis force, $\mathrm{V} \ell \mathrm{c}, \mathrm{Vrc}$ are linear velocities of transportation and relative motion of point $\mathrm{C}$

\section{Conclusion}

The result of the performed work is a system of inhomogeneous differential equations of secondary order, which are the basis of mathematical models of combined manipulator in the mode of load lifting with synchronous movement of the boom and the column. The obtained system of equations allows analyzing influence of parameters of kinematic scheme on the level of loads on processing equipment in the process of modeling $(\ddot{\varphi}, \ddot{\alpha}, \mathrm{L}$, LK , $\dot{\varphi}, \varphi, \dot{\alpha}, \alpha$, OC, $\left.19, \alpha_{2}, \beta, l, \gamma_{1}\right)$, as well as analyzing weight value of load and processing equipment (mПР.C, 
mПР.К). Besides, by changing the rotation rate of shafts of hydraulic pumps motion rate of cylinder rods are changed and, consequently, an absolute velocity of point of reduction of mass of the boom and the load (point C), angular velocity and angular acceleration of the boom and the column are changed as well. The equations allow estimating influence of these factors on amount of load on structural elements of processing equipment.

\section{References}

1. V. Poletaykin, P. Kolesnikov, A. Savelyev, G. Moiseev. Mechanization of Construction, 77, no. 12, 41-45 (2016).

2. V. Poletaykin, P. Kolesnikov, A. Savelyev, G. Moiseev. Construction Mechanization, 77, no. 5, 36-40 (2016).

3. D. Chernik, P. Kolesnikov. Journal of international scientific researches, 3(28), 123-128 (2016).

4. V. Poletaykin, P. Kolesnikov, Systems. Methods. Technologies, no. 2 (22), 50-55 (2014).

5. P. Kolesnikov, G. Moiseev. New materials and technologies in mechanical engineering, no. 18, 151$153(2013)$

6. V. Poletajkin, P. Kolesnikov. Mathematical modeling of technological processes of rotary loggers with a variable departure of freight (International Scientific Research, 2015).

7. V. Poletajkin Applied mechanics of forest hoisting-andtransport cars. (Monograph) (2010)

8. P. Kolesnikov Simulation of operating modes of the logger with variable embarkation of a load. (Monograph) (2007)

9. V. Muratov, V. Ilyin, V. Poddubny. Dynamic loadings of a hydraulic cylinder of the logger and adjustment of the safety equipment (TsNIIME, 1980).

10. Z. Emtyl, Improvement of kinematics, dynamics and design of timber industry hydraulic manipulators (2001).

11. G. Moiseyev, S. Teleshev, P. Kolesnikov, Relevant directions of scientific research, 2, no 5-4 (10-4), 200204 (2014)

12. V. Poletajkin, P. Kolesnikov., Coniferous boreal zone, XXVI, no 2, 278-283 (2009)

13. V. Poletaikin, Forest magazine, №6, 34-37, (2002)

14. V. Poletaikin, Bulletin of the Krasnoyarsk state agricultural university, № 11, 185-192 (2012)

15. I. Kilin, M. Kanun. Fundamentals of mechanics of robots. Dynamics of industrial robots (STI, Krasnoyarsk, 1992)

16. A. Yablonsky. Course of theoretical mechanics., P. 2.: Dynamics. (Moscow, 1966).

17. V. Poletaykin, I. Goncharov, Bulletin of the Krasnoyarsk state agricultural university, № 1, 46-52 (2014)

18. M. Bat, G. Dzhanelidze, A. Kelzon. Theoretical mechanics in examples and tasks, 2.: Dynamics (Moscow, 1968).
19. V. Poletaykin, S. Guskov, Systems. Methods. Technologies, (2014).

20. D. Volkov. Dynamics and durability of excavators (Mechanical engineering, 1965). 